\title{
Using an open digital space assessment on a course for new teachers in higher education
}

\author{
Francesca Robinson \\ Royal Holloway, University of London
}

\begin{abstract}
An assignment was devised - in an open online space - to enable participants on a oneyear initial teacher education course to: deepen and share their knowledge on a teachingrelated topic of interest; develop their digital skills; enable reflection on their experience of the task. After two cohorts had completed the assignment, a small research project was then carried out to explore participants' experience of and attitudes towards this type of assessment. Survey responses suggest that, overall, respondents found it to be a worthwhile activity that encouraged them to engage with the literature and reflect on their own and others' practice. Respondents also critiqued the task implementation and commented on how they would adapt it within their own teaching contexts to encourage fuller engagement with the tasks. In the light of the responses, the assignment was redesigned for the third cohort.
\end{abstract}

Keywords: teacher education, digital skills, social media, assessment for learning

\section{Introduction}

As teacher educators, part of our role is to contribute to the professional development of student teachers, to show them new ways of educational thinking and to enable them to build on their knowledge of pedagogical methods and make connections between theory and practice (Lunenberg, Korthagen and Swennen, 2007). One way to do this is through building a community of practice (Gibbs, 2013, p.6) and this can be fostered through a digital assignment that relates to a professional context and encourages participants to take an active role (Sambell, McDowell and Montgomery, 2012). If the assignment enables students to be creative in their response, they might be more likely to take ownership of their learning. In higher education (HE), features associated with creativity across teaching contexts include being imaginative, exploring, taking risks and providing a novel, suitable response to an open-ended task (Jackson, 2006; McWilliam, 2009). With these points in mind, I devised an assignment that required the participants of a one-year initial teaching course to contribute posts to an open online space. From a prior study three years earlier - an investigation into course participants' preferred learning methods, their experiences of using a range of social web tools and their interest in using such tools in teaching - it had become clear to me that the use of several current technologies needed to be embedded within the course (Robinson, 2017). To apply a blog or wiki to teaching was something a large number of participants said they would like to learn more about and so I began to think about how to include a meaningful task using an open digital space. At that time, I was also reflecting on the fact that many of the participants' assessed reflective accounts of their teaching practice were full of interesting insights and tips on teaching and learning that would only ever be 
read by the markers; it seemed a shame not to share these with a wider audience. However, as Instone (2005, p.305) states, it is important to consider how, on a course like this, to engage busy participants without overloading them. Moreover, as this would be an opportunity to develop digital skills, I should need to consider carefully which digital space to choose.

\section{Developing digital skills in an open space}

It can be argued that giving student teachers the opportunity to develop their digital skills is essential in contemporary society (Dohn, 2010, p.143). In this task, they would potentially touch on several elements of the Jisc digital literacies model (2014): learning how to use and work in a new online space; contributing - as part of a large group - posts to the creation of a teaching-related digital resource; building on others' posts; and reflecting on their digital reputation when choosing their online identity.

One of the benefits of using an open space - as opposed to an activity in a virtual learning environment (VLE) - is that it can enable participants to begin to experience open educational practice and to consider open teaching, which Couros (2009, p.235) defines as the "facilitation and promotion of learning experiences that are open, transparent, collaborative, and social." However, as Hegarty points out $(2015$, p.6), how far this practice can be considered truly open is questionable, as, even though the space would be publicly visible and posts could be shared through social media, only participants on the course would be invited to contribute. Yet perhaps one of the main reasons for using such an open digital space as a blog is that openness can encourage innovation and experimentation (Weller, 2010; Oravec, 2003). Producing work for an audience other than the teacher can be a strong motivator that encourages contributors to make more of an effort (Wood et al., 2015; Wheeler, 2011). Another potential benefit would be that participants could continue to refer to, add to or share posts from within the space after the end of the course (Instone, 2005, p.306). This is important because sharing and commenting on posts through social media is an increasing trend in teacher professional development; it would appear that a growing number of teachers are keen to share their expertise and reach out to like-minded others (McCulloch, Mclntosh and Barrett, 2011, p.4).

\section{Assignment task}

The task involved contributing posts on teaching and learning to an online space, thereby creating a useful digital resource for fellow teachers in HE. It was designed with a selfdirected approach in mind in order to encourage deep learning (Dohn, op.cit., p.143). The assignment brief was:

Discuss critically one theme related to teaching and learning in HE that sparks your curiosity, with reference to the literature. This should be on a topic that would be considered to be useful and of interest to others. You may wish, for example, to discuss an article you have read or a video you have watched. Images and video clips can be added too. 
The intended learning objectives of the task were:

- to participate constructively in an online community of learners;

- to discuss critically a relevant topic within teaching and learning in HE;

- to evaluate the uses of the digital space and learning activity (not formally assessed)

By their nature, online spaces can enable freer activities and I should have preferred not to assess the task, but felt this necessary to make it a valued activity and to ensure equal participation. By making the task open-ended and having broad learning outcomes, I hoped that participants might provide an imaginative response.

Choosing the right platform was crucial: for many participants, it might be their first experience of contributing to an open space. In order to encourage teachers to use social media with their students, we need to think about how we can make the technology we use easier to access and use (McCulloch, Mclntosh and Barrett op.cit., p.29). Their experience of using technology in education as students or trainee teachers might well have impact on their confidence and interest in exploring its use in their own teaching practice. I considered Wikispaces and Wordpress as platforms; I rejected the latter because, while tags can be added to indicate post topics, so many students would be working in the space that several posts might go unnoticed. I opted for Wikispaces because each page title can be part of a neat, extensive list to one side and so it lends itself well to this type of resource creation. I also found that it has an intuitive interface and so editing it is relatively straightforward. The space would also enable participants to choose how much to reveal about themselves (Oravec, op.cit., p.229). The fact that participants could also choose to be anonymous was essential in ensuring that the space enabled a "low threat, high challenge" task (McWilliam, 2009, p.289). This, I hoped, would make it less of a "risky space" (Instone, op.cit., p.307), so that they might feel they could openly discuss a topic of interest to them.

Another important aspect to consider was how much support to give. As Wheeler (op.cit., p.187) argues, we need to strike a balance in terms of the amount of support given in an online space; in response to his use of an open wiki in initial teacher training, some of his students said in their feedback that they would have liked training in how to use it effectively. I therefore gave guidance on joining and editing the space and put the College guidelines for use of social media in the course handbook. I added an example of an educational blog post to Moodle and set up pages with such broad suggested themes as 'assessment' and 'metacognition'. Participants could also add pages with their own themes.

\section{Assignment evaluation - first and second cohort}

During the first year, several observations were made:

- Initially, during course workshops, some participants asked what they should write, even though I had given them an example of a short blog post. That it was a blank space was perhaps somewhat overwhelming for some, as Wheeler (op.cit., p.183) suggests. I therefore recommended that they should wait until some posts were added, because being able to observe how others do a new task is a good way of encouraging peer learning. As Couros 
(op.cit., p.233) found, those who are more unsure become more comfortable once they see what might be expected of them.

- Participants wrote posts on a broad range of topics within the space. Some linked theory to classroom practice, whilst others wrote about the impact of wider issues, such as the importance of Arts subjects in HE. A few participants added images or video links. Several added new pages for their posts whilst many added posts underneath others within pages with such broad titles as 'assessment'.

- Interestingly, two participants from the previous year who weren't required to contribute to the space as part of their assessed tasks opted to do so. I linked to one of these posts when I gave feedback on another participant's portfolio, as they had discussed similar aspects in their teaching evaluation.

- As in a typical wiki space, one participant edited and built on another's post, which was something I hadn't anticipated. I therefore let the first contributor know that they could leave it as it was or add their original post to a separate page if they weren't happy with it. This made me consider the importance of making the task clearer for the following year, given that they were working in a 'wiki' space.

- Whilst most participants chose usernames that didn't identify them, one person wrote his name at the bottom of his post.

Based on these observations, I made the following additions to the task guidelines: participants could work together on a post, but their individual contributions needed to be made clear; if they wished to build on someone's post, they should ask permission first; they could refer to a post from the previous year's space by linking to it. I made a screencast of how to join the space, as further support for participants with less or no experience of editing a wiki or blog. I also added to the assignment outline (which appears in the course handbook sent to them before their introductory day) a link to the previous year's digital space.

I initially planned to ask the second cohort to contribute to the same wiki space. However, since there were already many links to pages on the left-hand side, I created a new one. As I also wanted to encourage participants to experiment more, I extended the guidelines to include varied post formats, such as audio-recording or video, together with a comment option so that participants might add comments/links when reading each other's posts.

During the second year, I observed that:

- in contrast to the previous year, very few questions were asked during the course introductory days about the digital assignment - perhaps because participants could refer to the screencast and had the chance to see posts by the first cohort;

- although there was an option to comment on other posts, only a few participants did this.

- several participants in their posts linked to other posts from the previous wiki space, indicating that there was some interest in reading other contributions. 


\section{Research study}

At the end of that year, I planned to explore the second cohort's experience and views as part of a small research project. As Dohn (op.cit., p.146), reminds us, learning activities can have the intended outcome of developing knowledge and skills or, "in the holistic project, of transforming, utilising and making integrated sense of the experiences, perspectives, knowledge and attitudes" within a given setting. A task in an online space might lead to the former outcome even if the latter focus was the intended one. I was therefore keen to explore participants' perspectives of the task. The research question was:

How far do participants value and engage with the digital assignment?

\section{Method}

During the course introductory days, I gave an outline of the research and invited participation in an end-of-year survey that would help me to gain insight into participants' attitudes to and experience of the task. I stated that, though I might look at their individual posts, I was more interested in learning about their perspectives of this type of assignment. Although 45/108 signed a participation consent form, I anticipated that the eventual number of responses would be much lower, as less than half of the cohort usually complete the course within a year and some of those who did finish it might be suffering from end-ofcourse survey fatigue.

I chose an e-survey for its provision of anonymity for responses; as the course leader was also asking for feedback on a newly-designed assessment, it was important that respondents felt they could be honest. The first question contained a three-point scale and a comment box, whilst the remaining four questions were entirely open-ended. It was reiterated in the survey that participation was optional and that the responses would be anonymous.

Following portfolio submission by thirty-three participants, the e-survey was sent out to those who had given their consent to participate in the survey $(n=14)$, and nine responses were received in total. The open-ended responses were coded and grouped into themes using thematic analysis (Braun and Clarke, 2006) and compared to the literature.

\section{Findings and discussion}

\section{Perceived value of the task}

Two respondents saw the value of being pushed to experience this type of online task:

"It prompted me to search for material which could be visually represented."

"Interesting engagement with an e-tool, good to provoke us to use it."

It was also seen as a chance to develop their understanding of how theory relates to teaching practice:

"Without the assignment I would never have gone into the theory which underpins best practice." 
"I read through other topics that interested me and might be relevant to my teaching."

Some respondents could see the potential relevance and value of the task to their own students:

"It mixes things up a bit."

"I think it may be particularly useful for quieter students who may be less comfortable with speaking out during seminars or tutorials."

"Good platform for sharing ideas."

"By only having to write a short piece of work students might feel more inclined to contribute and the use of the discussion feature is useful."

However, one comment revealed that there perhaps needed to be more clarification on the style of writing:

"I personally understood the wiki task as different to a classic essay writing...It is a good idea, but I did not particularly like the implementation."

This comment made me reflect on how student-teacher expectations can differ and that mine needed to be made even more explicit. I had left the topic, format and style of post entirely up to participants, with, for simplicity, only one marking criterion. As a result, in several posts, more attention was given to content than to the style (though I have found, in general, that the style varies and that some blog posts do, in fact, have more academic formality).

A further aspect commented on was how to adapt or improve upon the task in different teaching contexts. For these respondents, there was a question concerning participation:

"I would use a collaborative online space with my students...provided students are engaged in using the space and the space is monitored."

"Only if ways could be found to encourage wider participation. Left voluntary, I don't think it would work."

\section{Engagement in task beyond assignment requirements}

The assignment asked participants to post to the space on a teaching-related topic of interest to them, but, whilst reading and commenting on other posts was encouraged, to do so was optional. In spite of this, eight of the nine respondents stated they had read or would read other posts. One respondent, in addition to reading other posts, had commented on them and attributed the lack of responses to the fact that comments weren't compulsory:

"I have read several...I also left a few comments/questions but didn't get a response...perhaps not many others used the wiki as a space for learning and

Wheeler (op.cit., p.182) notes that leaving this aspect optional can have a negative impact if not all participants are checking back for any comments/questions and responding to them. Though I did see a detailed response to one of the comments, it had been made at a later date. I concluded it can be demotivating for those willingly engaged in making comments not 
to receive a response in a shorter timescale. A conundrum: Do we need to assess comments and risk the possibility of lower-quality responses because they've been made obligatory?

As the digital space could be viewed by anyone with the link, I hoped that participants might wish to share their own or others' posts on social media so that other teachers might benefit from reading them, as Instone suggests (op.cit., p.36). Three respondents commented that they might share their posts through other platforms, but five of the nine participants didn't intend to do so. Two respondents stated they wouldn't because they didn't participate in social media, whilst another person mentioned the variation in quality of posts:

"I might mention an idea I came across in others' posts but I wouldn't share posts wholesale as...there is a sense of 'no quality control about them'."

With regard to quality, as Bryson and Hand (2007) propose, there are several reasons why some participants may appear to make more effort than others - for instance, it could be a result of our curriculum design or implementation (such as assessment workload). As this comment reveals, the amount of time it takes to craft a well-written post can be a contributing factor:

"...my post was written in a rush so I would want to amend it before sharing it through other platforms."

An apparent lack of effort could, however, also be down to a lack of interest in teaching. This raises the question of what being a professional teacher means and whether all online contributions are worth sharing (McCulloch, Mclntosh and Barrett, op.cit., p.29).

\section{Discussion and next steps}

The assignment involved participants' contributing posts within an open digital space, thereby creating an HE teaching and learning resource of potential interest and use to fellow teachers. The respondents' comments revealed: the aspects they found to be of value; some of the limitations of the task; and, importantly, how they could adapt or improve on this task within their own teaching practice.

The small sample size is, however, a major limitation of this study, representing the views of just over a quarter of the participants who completed the assignments that year. In future, a similar survey could be sent out earlier to encourage more participation and make the findings more representative of the entire group. Yet, whilst the responses are not representative of the cohort as a whole, many of the comments helped me think further about how the task could evolve, including looking at the possibility of opening it up to participants on a similar course in another university.

For the third cohort, I changed the task to put more emphasis on sharing teaching ideas: participants were required to prepare a shorter post, in any format, on a novel way of teaching something and to post it on the page of the department they were teaching in. This could be more helpful because, as Gibbs (op.cit., p.6) admits, most teachers he has met have found his practical guides and tips to be invaluable, with a far greater readership than 
his research articles. In an effort to address possible variation in the quality of posts, I shared, on the introductory days, strong examples of shorter posts within exemplar portfolios and on Moodle, so making explicit my expectations of quality.

To encourage more discussion and sharing of ideas within the space, I also required participants to comment on at least one post, preferably on the page of another department, adding their own ideas or links to teaching tips. I hoped that, by reading posts from teachers in different departments, participants might ultimately feel more confident about trying out new teaching methods within their discipline. As Malcolm and Zukas (2000) argue, crossdisciplinary professional development can enable new thinking, in addition to department-led communities of practice. Finally, in order to focus more on how the task related to professional development and to encourage sharing of posts through social media networks, the first learning objective became:

to create a digital resource for and participate in an online teaching community.

\section{Assignment evaluation - third cohort}

- I observed that, overall, the posts were more concise and had much more of a practical focus.

- As I was writing this article, the first participant to post from the third cohort made and shared, through her YouTube channel, a short, engaging Videoscribe video that linked theory to practice. This was the first time someone had posted in a different format and, whilst it didn't appear to encourage anyone else to experiment with alternative media, it received several enthusiastic comments.

- Whilst most participants now added their name to their post and comment, some still chose to remain anonymous. Most participants commented on posts on the pages of other departments, but several also commented on posts on their own department's page. It was good to see that many participants offered further ideas and twists on the teaching methods suggested, as well as links to articles and posts from previous wiki spaces.

- At the end of the year, I decided that the same space would be used for the fourth cohort, since the number of pages had already been restricted by the number of departments and the posts were generally now more concise.

Unfortunately, the Wikispace service ended this year, but I have been able to save all of the posts from the previous Wikispace assignments as PDFs. After reviewing the options, I decided that a Google site will now be used for the assignment, as the pages can be laid out in a similar neat way on the left-hand side. I consider it important to keep using an open digital space, for that can be motivating for participants and they can, if they choose to do so, refer to it in future.

\section{Conclusion}

It can be argued that, as there is growing evidence of the educative benefits of social media tools (McCulloch, Mclntosh and Barrett, op.cit.), educational developers should be using them to support new teachers with online professional development. Introducing these in 
contextualised tasks within initial teacher education courses might have more impact than larger institutional attempts to improve teaching (op.cit., 2013).

Moreover, although it is difficult to say how far the task reported on here has enhanced or will enhance teaching practice, I hope that it has encouraged reflection and deep engagement with a range of topics. When teaching in future, participants may design a similar task based on their own critical evaluation of the assignment from an experiential viewpoint. They might also be open to designing, evaluating and adapting the activity with their students.

Another important consideration is that, even though not all of the participants will go on to teach in universities after the course, they will need continually to update and develop their digital and professional skills in any work environment. For those who do, their contributions can also be seen as a positive digital footprint (McCulloch, McIntosh \& Barrett, op.cit.) and used as evidence of their interest in and commitment to teaching.

As a final point, developing this task has been an enjoyable experience that has offered plenty of opportunity for critical reflection on my own task implementation. As educational developers, I believe we have a responsibility to experiment with new teaching methods. As Lunenberg, Korthagen and Swennen (op.cit.) suggest, we can make it clear to the new teachers with whom we work and learn that this involves risk-taking and discuss why this might be advantageous to teachers and students.

\section{Reference list}

Bryson, C. and Hand, L. (2007) 'The role of engagement in inspiring teaching and learning.' Innovations in Education and Teaching International, 44(4), 349-362. Available at: http://www.tandfonline.com/doi/abs/10.1080/14703290701602748 (Accessed: 19 July 2016).

Couros, A. (2009) 'Open, connected, social-implications for educational design.' CampusWide Information Systems, 26(3), 232-239. Available at: http://www.emeraldinsight.com/doi/full/10.1108/10650740910967393 (Accessed: 2/2/2016).

Dohn, N.B. (2010) 'Teaching with wikis and blogs: Potentials and pitfalls.' In: Proceedings of the 7th International conference on networked learning (pp. 142-150). Available at: http://www.networkedlearningconference.org.uk/past/nlc2010/abstracts/PDFs/Dohn.pdf (Accessed: 4/6/2016).

Evans, P. (2015) 'Open online spaces of professional learning: Context, personalisation and facilitation.' TechTrends, 59(1), 31-36. Available at:

http://link.springer.com/article/10.1007/s11528-014-0817-7 (Accessed: 8/4/2016).

Gibbs, G. (2013) 'Reflections on the changing nature of educational development.' International Journal for Academic Development, 18(1), 4-14. Available at: http://www.tandfonline.com/doi/full/10.1080/1360144X.2013.751691\#.UeEoQzs3vA4 (Accessed: 4 April 2013). 
Hegarty, B. (2015) 'Attributes of Open Pedagogy: A Model for Using Open Educational Resources.' Educational Technology, 4. Available at:

https://upload.wikimedia.org/wikipedia/commons/c/ca/Ed Tech Hegarty 2015 article attrib utes of open pedagogy.pdf (Accessed: 7/6/2016).

Instone, L. (2005) 'Conversations beyond the classroom: Blogging in a professional development course.' In: Proceedings of the 2005 Ascilite conference, Brisbane. Available at: http://www.ascilite.org/conferences/brisbane05/blogs/proceedings/34 Instone.pdf (Accessed: 18/3/2016).

Jackson, N. (2006) 'Creativity in higher education: What's the problem?' Educational Developments, 7. Available at:

http://www.seda.ac.uk/resources/files/publications 20 eddev7 1.pdf (Accessed: 5/6/2016).

Jisc (2014) Developing Digital Literacies. Available at: https://www.jisc.ac.uk/fullguide/developing-digital-literacies (Accessed: 4/1/2016).

Lunenberg, M., Korthagen, F. and Swennen, A. (2007) 'The teacher educator as a role model.' Teaching and Teacher Education, 23(5), 586-601. Available at:

http://www.sciencedirect.com/science/article/pii/S0742051X06001685 (Accessed: 15/7/2016).

Malcolm, J. and Zukas, M. (2001) 'Bridging pedagogic gaps: conceptual discontinuities in higher education.' Teaching in Higher Education, 6(1), 33-42. Available at: http://www.tandfonline.com/doi/pdf/10.1080/13562510020029581 (Accessed: 29/6/2013).

McCulloch, J., Mclntosh, E. and Barrett, T. (2011) Tweeting for Teachers: How Can Social Media Support Teacher Professional Development? Pearson Centre for Policy and Learning. Available at: http://www.itte.org.uk/sites/default/files/Tweetingforteachers.pdf (Accessed: 9/12/2016).

McWilliam, E. (2009) 'Teaching for creativity: from sage to guide to meddler.' Asia Pacific Journal of Education, 29(3), 281-293 Available at:

http://www.tandfonline.com/doi/abs/10.1080/02188790903092787\#.V44lgdlrLcs

(Accessed: 20/4/2016).

Oravec, J.A. (2003) 'Blending by blogging: Weblogs in blended learning initiatives.' Journal of Educational Media, 28(2-3), 225-233. Available at:

http://etec.ctlt.ubc.ca/510wiki/images/0/05/Oravec.pdf (Accessed: 20/4/2016).

Sambell, K., McDowell, L. and Montgomery, C. (2012). Assessment for learning in higher education. London: Routledge. ISBN: 978-0-415-58657-3. 
Robinson, F. (2017) 'Embedding TEL in an initial course in Teaching \& Learning in HE: a codesign approach.' Compass Journal of Learning and Teaching 10(1). Available at:

https://journals.gre.ac.uk/index.php/compass/article/view/368 (Accessed: 27/4/2017).

Weller, M. (2011) 'The openness-creativity cycle in education.' Journal of Interactive Media in Education, 2012(1), Article 02. Available at: http://jime.open.ac.uk/articles/10.5334/201202/ (Accessed: 5/4/2016).

Wheeler, S. (2011) 'Using Wikis in Teacher Education: Student-Generated Content as Support in Professional Learning.' Web 2.0-Based E-Learning: Applying Social Informatics for Tertiary Teaching: Applying Social Informatics for Tertiary Teaching. Hershey:

Information Science Reference, pp. 180-191. ISBN: 9781605662947

Wood, J., Griffiths, M. and Kutar, M. (2015) 'Ecstasi project: using technology to encourage creativity in the assessment process.' Available at: http://eprints.lincoln.ac.uk/19975/

(Accessed: 20/4/2016). 